\title{
SPORTS TOURISM
}

\section{MARINA GOZALOVA ${ }^{1}$, ALEXEY SHCHIKANOV², ALEKSANDR VERNIGOR ${ }^{3}$, VARDAN BAGDASARIAN ${ }^{4}$}

\author{
Moscow State University of Tourism and Service, Department of Foreign Language ${ }^{1}$, \\ Department of Mathematics and Natural Sciences ${ }^{2}$, Department of Service, \\ Department of Foreign History ${ }^{4}$
}

\author{
Mailing address: Marina Gozalova, Moscow State University of Tourism and Service, Department of Foreign \\ Language, 99 Glavnaya Street, Pushkin district, item Cherkizovo, 141220 Moscow, \\ tel.: +7 926 2648708, fax: +7 495 9933317, e-mail: mgozalova@mail.ru
}

\begin{abstract}
Introduction. This article is devoted to sports tourism. The purpose of this article is to examine theoretical material on sports tourism, to analyze sports tourism in Russia and to search for promising areas for the study of sports tourism in our country. Material and methods. In this part the authors develop the idea of the role of doing sports and keeping fit. For anyone who really wants to be healthy, fitness has become an integral part of their lives. Results. The purpose of this research is to study theoretical material on sports tourism, to analyze sports tourism in Russia and to search for promising areas for the study of sports tourism in our country. On the basis of their research the authors come to the conclusion that sports and tourism are interconnected. There are important factors affecting the situation of sports tourism in Russia. The paper examines sports tourism attractions in Russia. Conclusion. The authors conclude that there exists a high correlation dependence of foreign and domestic development of sports tourism on resources allocated for sports infrastructure. All in all, sports tourism tours draw visitors to their favorite sporting event, facility, or destination throughout the world.
\end{abstract}

Key words: tourism, good health, sport, healthy living, sports tourism

\section{Introduction}

Certain sharp-witted people are fond of saying that what they really love is the universe. The whole world turns out to be far more wonderful, and even far more interesting, than they expected. It is the universe itself which should be valued above all. So people should enjoy living in this wonderful world. Scientists say that in the future people will live longer. With healthier lifestyles and better medical care the average person will live to 90 or 100 instead of 70 and 75 like today. Incurable diseases will be cured. But that is tomorrow. And today? We are always in a hurry. We have no time to enjoy ourselves. We all know that the healthier we are, the better we feel. The better we feel, the longer we live. So why not take care of ourselves? Unfortunately a lot of people are not fit nowadays. It is a big problem today. If you want to feel fit you should take up one kind of sport or another.

\section{Material and methods}

Sport is probably as old as humanity itself. It has developed alongside the development and growth of mankind. We can hardly overestimate the meaning of sport in our lives and dayto-day activities, because its main purpose is to bring up a harmoniously developed generation - a generation of strong and healthy people. Sport makes our bodies strong, quickens our reactions, and shapes the wits. It also prevents us from getting too fat, gives us valuable practice in making our eyes, brains and muscles work together and makes us more self-organized and better disciplined.

For some people there is nothing so exciting as traveling.
And they really travel a lot. Traveling is the favorite occupation of almost everyone. We are taught by historians that many thousand years ago our ancestors traveled from one place to another because they were seeking excitement. Perhaps the historians are right. Obviously people moved from one place to another because they hated the idea of sitting in the same place. In fact they were fond of traveling. They liked gaining new impressions of the surrounding world, which was so beautiful that they did not take all the dangers into account. Hunting, fishing, picking berries and fruit appeared later than traveling. People killed wild animals when they were very hungry or when the animals showed that they were hungry and people were forced to kill them to protect themselves. The fitness boom of the past decades has led to a big rise in the number of people participating in sports and other physical activities. A healthy body becomes fashionable, an ideal of the life of today. Those who pursue the latest fitness trends are convinced that staying in good physical form requires much more than regular exercise and balanced meals. For anyone who really wants to be healthy, fitness has become an integral part of their lives. There are many opportunities for keeping fit. First of all, it is necessary to exercise. People of different ages can design exercises that suit them. Running, jumping, swimming, bending and stretching are among the most popular exercises. Many people prefer jogging, which is the cheapest and most accessible sport. Walking is a very popular activity too.

Even moderate physical activity can protect against heart disease and strokes as well as improve general health and quality of life [1]. Everyone can benefit from being a little more active. Making small changes like using the stairs instead of the lift or walking or cycling instead of taking the bus can help people lead a more active, healthier and enjoyable life. 
But nowadays people travel for different reasons [2]. They travel to see other countries and continents, modern cities and the ruins of ancient towns, they travel to enjoy picturesque places, or just for a change of scenery, to relax or do business. Regardless of the motive, all means of travel have their advantages and disadvantages. And people choose according to their plans and destinations. Never before in the history of the world have businessmen traveled as much as they do today. It is not surprising because we are living in a world of growing international trade and expanding economic and technical cooperation. Though it is fascinating for the traveling tourist, it has become the most tiring of all occupations for many businessmen and experts. But business trips are very important because face to face meetings are more valuable and profitable for business than any other type of strategy. On a business trip people might meet colleagues and business partners for the first time. Often, colleagues from different countries experience cultural difficulties, that is, they are surprised by what strike them as strange social conventions in a new place. Different cultures do things differently. Management styles also differ from country to country. It is often useful, when doing business in a foreign land, to get some advice from a special agency which consults on questions of international business.

But are there any practical rules for healthy living and traveling? There are hardly any rules. The formula for healthy living and traveling cannot be put into words - it can only be practiced.

Many people say: if you want to see a place, go on foot. And it is no wonder. The walker leaves the dull, broad highway and follows little winding lanes where cars cannot go. He takes mountain paths through the heather, he wanders alongside quiet lakes and through shaded woods. He sees the real country - the wildflowers, the young birds in their nests, the deer in the forest; he feels the quietness and calm of nature. And besides, you save a lot of money by traveling on foot. No one can deny that walking is the cheapest method of traveling.

People all over the world are very fond of sports and games. That is one of the things which unite people of every nationality and class. It goes without saying that while traveling people have to stay somewhere. So hotels nowadays play a big role. Each year more and more new hotels are opened. Sometimes it is even difficult to decide which to choose while traveling. There are luxury hotels, which seem expensive, B\&B hotels, where you get only breakfasts and a place to sleep, youth hostels, where you have to serve yourself and many other places to stay. Some people enjoy staying in a hotel, where all the necessary sport facilities are provided for them.

\section{Results}

Therefore, it can be concluded that sports and travel have become an integral part of modern society. Regardless of people's reasons for traveling - for business or pleasure - they prefer to combine their trips with recreational activities, i.e. sports. 150 people from different walks of life: businessmen, students, young families with children and the elderly were interviewed. It was found that $90 \%$ of respondents prefer active leisure and only $10 \%$ (families with children) prefer passive recreation.

Tourism is the world's largest and fastest growing industry [3]. In recent years there have been increases in international tourism for the purpose of experiencing another culture. There is a wide-spread opinion that the economic impact of tourism is always positive while the social and environmental impact is always negative. Indeed, increases in regional incomes due to tourism are readily identifiable, as are numerous host-tourist conflicts and destruction of the environment and local cultures. However, tourism can have both positive and negative out- comes for residents in communities when sharing and preserving their culture and natural environment could be seen as conflicting goals. In this paper we will briefly try to establish the significance of the relationship between sport and tourism and discuss how sports tourism might be conceptualized and understood. Research in the field of sports tourism has burgeoned over the last 15 years. The focus of these early works was on advocacy, attempting to establish sports tourism as a legitimate field of study with a potentially significant range of effects. Sports tourism is an independent and socially-oriented field, and a lifestyle that is shared by a considerable percentage of society. It is an effective means of furthering the spiritual and physical development of the individual.

The purpose of this article is to study theoretical material on sports tourism, to analyze sports tourism in Russia and to search for promising areas for the study of sports tourism in our country.

There are some articles relating to sport and tourism which, while remaining largely descriptive, outlined the range of economic, socio-cultural, environmental and health effects of sports tourism. In the late 1990s and early 2000s, a range of authors carried out more detailed examinations of the sports tourism field in relation to policy, destination, development, seasonality, participation patterns, economic impacts and spectators [4]. The existence of these works demonstrates academic interest in the area, while their content clearly establishes sports tourism as a real and significant phenomenon in contemporary society. In recent years the field of sports tourism has clearly grown, alongside developments in outdoor and adventure tourism, skiing and winter sports.

Implicit in this research is the recognition that sports tourism is a significant cultural, social and economic phenomenon. There have been a number of attempts to define sports tourism. We define sports tourism as all forms of active and passive involvement in sporting activity, participated in casually or in an organized way for non-commercial or commercial reasons and necessitating travel away from home. Sports tourism simply identifies tourism activities involving sports. It is the simple combination of both sport and tourism.

Sport can be seen as involving some form of activity, be it formal or informal, competitive or recreational, active or passive. Furthermore, sport also involves people as competitors and/or participants. Passive participants are spectators and active participants are competitors. Also, there are activities that are sometimes participated in alone, e.g. mountaineering and running.

Similarly, tourism involves people, as co-travelers and/or hosts. It is rare for a tourist to complete a trip without encountering other travelers. Tourism also involves visiting places outside of the tourist's usual environment. There is, of course, a travel element, but this is either an instrumental factor connected with arriving at an unusual place, or the travel takes place in or through unusual places.

Considering the interaction of these features of sport and tourism, sports tourism could be understood as a unique interaction of activity, people and place. Consequently, the definition used in this article is as follows: sports tourism is a social, economic and cultural phenomenon arising from the unique interaction of activity, people and place.

There are several types of sports tourism: tourism with sports content, sports participation tourism, sports training and sporting events. In considering the features of these sports tourism types, perhaps the most obvious feature is that sports tourism may involve multi-sport or single-sport participation.

Each of the sports tourism types discussed here may also involve both active and passive participation. Many sports spectators consider themselves to be much more than passive participants, although they do not actively take part in the sport 
itself. Such spectators feel that they are interacting with the active participants and, as such, might be described as experiencing the sport through the participants. But some active participants are really very active. They prefer speed, excitement, danger. They find all of these in the different extreme sports that have become popular in the past 10 years. Take bungee jumping or skysurfing, for example.

Winter sports have always had an element of danger [3], for example snowboarding, which has all the excitement of surfing but is even more dangerous than skiing. Probably the most dangerous of all the new winter sports is snow rafting, while ice diving is only for those who are absolutely crazy. Of course, water sports have always been fun.

The features described above are: multi-sport, single-sport, and active participation, which may be a feature of every type of sports tourism. Sporting events may be either multi-sport, e.g. the Olympic Games, or single-sport, e.g. the FIFA World Cup. They may be active for participants and passive for spectators. Sports tourism is associated with travel to various sporting events. The popularity of this type of tourism is growing. It allows participants to engage in selected sports (skiing, swimming, sports fishing, hunting, etc.).

Sports tourism involves travel to sporting events in different countries and regions. It can be further divided into professional and amateur tourism.

Broadly defined, sports tourism includes travel away from one's primary residence to participate in a sports activity for recreation or competition, travel to observe sports at the grassroots or elite level, and travel to visit a sports attraction such as a sports hall of fame or water park. Sport, in itself, is defined in various ways and from different perspectives. Sport and active recreation have become very large and successful industries worldwide.

Given the trends emerging in both the tourism and sports sectors, it is not surprising that significant growth is also occurring in travel for sports related purposes. In fact, this growth is also linked to another trend: that of traveling for specific purposes, of which sporting activity is one.

Sports tourism attractions are destinations that provide the tourist with things to see and do related to sport. Attractions can be natural (parks, mountains, wildlife) or manmade (museums, stadiums, stores). General characteristics represented in this core area of sports tourism include visits to:

- state-of-the-art sports facilities and/or unique sports facilities that generally house sporting events, such as stadiums, arenas and domes;

- sports museums and hall/walls of fame dedicated to sports heritage and to honoring sports heroes and leaders;

- sport theme parks including water parks, summer ski jumps, bungee jumping;

- hiking trails developed for exploring nature;

- sports retail stores.

Sports tourism resorts are well-planned and integrated resort complexes with sports or health as their primary focus and marketing strategy. In many situations, these vacation centers offer high-quality facilities and services to the sport tourist.

Sports camps are hosted at resorts, universities and in the wilderness, and offer organized, intensive training sessions in just about every sport imaginable. There are camps for traditional sports such as baseball, basketball, golf, soccer, tennis, volleyball, figure skating, swimming, gymnastics, hockey and sailing, as well as more adventurous camps that lead participants down white-water rapids, over rugged canyons, or off steep cliffs (hiking, biking, paddling, horseback riding or climbing). Although sports camps are commonly considered an activity for young people, the number of family and adult camps has increased in recent years. Fantasy sport camps have been especially successful in capturing the adult market.

The sports tourism cruise category includes all boat-related trips that have sports or sporting activities as their principal marketing strategy. Many ships built today resemble hotels and resorts and have unique sports installations. They also utilize guest sports celebrities as a marketing tool. To further satisfy the sport tourist, cruise ships often arrange special transportation to provide guests opportunities for golf, tennis, snorkeling, waterskiing, etc., in unique and varied water environments. Other planned activities include onboard sports competitions and/or modified games (e.g. a golf driving range on deck), and special presentations or clinics from invited sport celebrities. Cruiseand-drive programs also exist, whereby tourists board private vehicles and are taken to desired sports destinations. Private yachts that sail directly to the sports destination of choice can also be chartered. The use of watercraft for sporting activities (e.g. recreational and competitive sailing, jet skiing) is another important dimension in this category.

Sports tours may include visits to sport museums and stadiums as well as events or games in multiple locations lasting anywhere from one to two weeks. Some sports tour companies cater to common interest groups, while others specialize in corporate incentive programs, educational tours to a specific conference or location, or outdoor adventure challenges. The sports tourism event category refers to those sports activities that attract a sizable number of visiting participants and/or spectators. Visitor types vary depending on the sporting event, as some events are obviously more spectator-driven than others.

Our research has led us to conclude with absolute certainty that a combination of sports and tourism is the best way to keep fit. There is always a kind of sport which will suit you, and there are many different kinds to choose from. If you like team games, try hockey, football, volleyball or basketball. Games you can play with a friend include badminton and tennis. And if you enjoy doing things on your own, you might take up swimming, golf or athletics. We believe that everyone should do everything they can to be healthy. Good health is better than the best medicine. Physical exercise is very useful for making our bodies strong and keeping us fit and healthy.

Having examined the various types of sports tourism, we will now analyze the situation of sports tourism in the regions, towns and major cities of Russia.

Sports tourism entered the $21^{\text {st }}$ century as a relatively new but steadily growing part of the economy, one that exerts a profound influence on the socio-economic development of our country. Not long ago, Russian sports tourism was still developing, and Russia as a country held a very small share of the world tourism market. Tourists entering Russia accounted for about $5 \%$ of world tourist traffic. This is a low figure, given that the cultural-historical and natural potential of Russia is much higher than that of many countries with traditionally high tourist traffic.

Consequently, the Russian tourism industry was faced with the problem of finding a method for building an effective management system that would strengthen the market position of each Russian organization dedicated to serving tourists, and thus contribute to developing the tourist trade as a whole and to integrating Russia into the world tourism industry.

Russia's big cities have all had numerous opportunities to develop sports tourism, which cannot be said of the country's regions. But today we see how quickly sports tourism developed in the regions - so quickly in fact that our regions have been recognized by the WTO (World Tourism Organization).

Therefore, we would like to consider the tourism industry of the Russian Federation today as one of the most promising sectors of our economy, with the Krasnodar region serving as an 
example of successful development of the tourism industry in the Russian Federation. The Krasnodar Region has recently become one of the most successful sports tourism regions, not only in Russia but in the whole world. The region has a high proportion of inward investment in the sports tourism sector; investors are offered the most innovative projects and new jobs are created. The Krasnodar region today has access to international tourism activities.

Before any conclusions can be drawn, an overview is needed of the history of the development of tourism and sport in the Russian Federation (the USSR) and the emergence of sports tourism:

- 1927 (POT) pre-revolutionary Russian society of tourists. After the conference, it is renamed the Society for Proletarian Tourism and Excursions (OPTE);

- 1929 "Intourist”;

- 1930 sightseeing and sports tourism becomes a mass phenomenon;

- 1936 OPTE is liquidated and TEU (Tourist and Excursion Control) is established;

- 1937-1940 the structure of tourism is reorganized;

- 1945 the decision is made to resume the activities of TEU;

- 1946 TEU is established in the Kalinin region and Estonia;

- 1947 TEU is established in the Krasnodar;

- 1948 TEU is established in the Leningrad region. At this time, sports, amateur, family and children's tourism become widespread;

- 1958 "Sputnik", an international youth bureau, is founded.

The next research priority concerns knowledge of Russian sports tourism zones:

- West Tourism Zone: includes the Kaliningrad region and the Baltic Sea (water sports);

- Northwestern Tourism Zone: includes Saint Petersburg, Leningrad, Novgorod, Pskov, the Vologda region and the Republic of Karelia (hunting and fishing);

- Central Tourism Zone: Moscow, Vladimir, Kaluga, Ryazan, Smolensk, Tver, Tula, the Yaroslavl region (winter sports, hunting and fishing);

- South Russian Tourism Zone: The Belgorod, Bryansk, Voronezh, Kursk, Lipetsk, Orel, Penza and Tambov regions, as well as the Republic of Mordovia (summer and winter games);

- Volga Tourism Zone: The Republic of Kalmykia, Tatarstan, Mari El, Udmurtia, Chuvashia, and Astrakhan, Saratov, Ulyanovsk, Samara, Volgograd, Ivanovo, Kirov, Nizhny Novgorod and the Kostroma region (extreme and water sports);

- Ural Tourism Zone: The Republic of Bashkortostan and Orenburg, Permskaya, Sverdlovsk and the Chelyabinsk region (winter sports);

- Priazovsk-Black Sea Tourism Area: The Krasnodar Territory and the Rostov Region (summer and winter sports);

- Caucasian Tourism Area: Stavropol Krai and the Republic of Adygea, Dagestan, Ingushetia, Chechnya, Kabardino-Balkaria, Karachay-Cherkessia, North Ossetia (mountain hiking);

- Ob-Altai Tourism Area: Altai and the Altai region and the Kemerovo, Tyumen and Tomsk regions (mountain hiking);

- Yeniseyskaya Tourism Zone: Tuva and Khakassia and the Krasnoyarsk region (winter sports);

- Baikal Tourism Zone: Republic of Buryatia and the Irkutsk and Chita regions (extreme water sports);

- Far East Tourism Zone: includes: Primorsky and Khabarovsk Krai, the Amur and Sakhalin regions (sports and adventure tourism);

- Russian North: The Komi, Sakha and Chukotka Autonomous regions, Taimyr, Khanty-Mansiysk, Evenki, Yamal-Nenets, Arkhangelsk, Murmansk, Kamchatka and Magadan (winter sports).

Our study has shown us what tourist areas are in high demand among fans of sports tourism. Russia is a huge country and is therefore able to satisfy all outdoor enthusiasts. The most important thing is to develop sports tourism.

Russia has every chance of becoming a top destination for sports tourism. According to estimates by the World Travel and Tourism Council (WTTC), by 2020 the global travel industry will produce goods and services amounting to approximately $\$ 9$ billion.

Inbound tourism is influenced by various factors, including measures to promote sports and physical culture in the country. From 2013 to 2015, there is a tendency to increase federal expenditures for the development of physical culture and sports. As a result, full funding will be provided for athletic and sporting activities included in the Unified schedule, interregional, national and international athletic events and sports activities for sports included in the program of the Olympic Games, Paralympic Games, activities to promote healthy lifestyles and the promotion of physical culture and sport.

As input parameters for our analysis, let us take the funds allocated for the development of sports infrastructure in the Russian Federation as variable $X 1$ (in billions of rubles - Appendix N 2k Federal Target Program "Development of physical culture and sports in the Russian Federation for 2006-2015”) [4], the percentage of foreign citizens entering Russia for sporting events (for 2004, the variable $X 2$ and the percentage of people regularly engaged in sports (\%) - variable $X 3$ and the "Strategy of tourism development in the Russian Federation for the period up to 2015”) [5] (tab. 1).

Table 1. Strategy of tourism development in the Russian Federation for the period up to 2015

\begin{tabular}{|c|c|c|c|c|c|}
\hline $\mathbb{N}^{0}$ & Year & $\begin{array}{c}\text { Visits by } \\
\text { foreign citizens } \\
\text { to Russia } \\
\text { for sporting } \\
\text { events } \\
\text { (mln trips) }\end{array}$ & $\begin{array}{c}\text { Development } \\
\text { of sports } \\
\text { infrastructure } \\
\text { in billions of rub. }\end{array}$ & $\begin{array}{c}\text { Percentage } \\
\text { of citizens } \\
\text { systematically } \\
\text { involved } \\
\text { in sports } \\
\text { (percentage) \% }\end{array}$ & $\begin{array}{c}\text { Percentage of } \\
\text { foreign citizens } \\
\text { entering Russia } \\
\text { (relative to 2004) }\end{array}$ \\
\hline 1 & 2004 & 1.752 & 0.98 & 11.6 & 1 \\
\hline 2 & 2005 & 1.776 & 1.01 & 12 & 1.01369863 \\
\hline 3 & 2006 & 1.8 & 1.143 & 13 & 1.02739726 \\
\hline 4 & 2007 & 1.832 & 2.695 & 15 & 1.0456621 \\
\hline 5 & 2008 & 2.008 & 2.27 & 17 & 1.146118721 \\
\hline 6 & 2009 & 2.176 & 2.747 & 20 & 1.242009132 \\
\hline 7 & 2010 & 2.28 & 2.89 & 23 & 1.301369863 \\
\hline 8 & 2011 & 2.384 & 3.396 & 25 & 1.360730594 \\
\hline 9 & 2012 & 2.52 & 4.345 & 27 & 1.438356164 \\
\hline 10 & 2013 & 2.72 & 5.069 & 29 & 1.552511416 \\
\hline 11 & 2014 & 2.8 & 4.536 & 30 & 1.598173516 \\
\hline 12 & 2015 & 2.88 & 8.713 & 32 & 1.643835616 \\
\hline
\end{tabular}

Let us consider the regression of $X 2$ on $X 1$, and the regression $X 3$ on $X 1$, and define an association between the aforementioned factors. As a result of these calculations we obtain table 2. 
Table 2. Regression of $X 2$ on $X 1$, and regression $X 3$ on $X 1$

\begin{tabular}{|c|c|c|}
\hline & X2 on X1 & X3 on X1 \\
\hline Multiple R & 0.893381712 & 0.992937 \\
\hline R-squared & 0.798130883 & 0.985924 \\
\hline Normalized R-squared & 0.777943972 & 0.984516 \\
\hline Standard error & 0.112533097 & 0.029716 \\
\hline Number of observations & 12 & 12 \\
\hline
\end{tabular}

\section{Conclusions}

The results of the research can be regarded as indicating a high correlation dependence of foreign and domestic development of sports tourism on resources allocated for sports infrastructure.

In conclusion we would like to point out that sports tourism tours bring visitors to their favorite sporting event, facility, or destination throughout the world. These tours may be selfguided or organized depending on access, location, and the nature of the activity. For example, many ski tour packages provide air travel, accommodation, local transportation, and ski lift tickets with no special guide or amenities. In contrast, some companies specialize in travel packages that fly fans to an away game, put them up in a hotel for a few nights, provide tickets to the competition, arrange for a cocktail party and schedule a postgame reception with players and coaches, and then return fans safely home.

\section{Literature}

1. Novikova N.G., Sakharchuk E.S., Ilkevich S.V. (2013). The factors of Russia's low competitiveness as a medical tourism destination. Applied Sciences 25, 104-108.

2. Gozalova M. (2013). Development of social competence in learning a foreign language. Bulletin of the Association of Universities for Tourism and Service 3, 49-52.

3. Hudson S. (2003). Sport and adventure tourism. Binghamton, NY: The Haworth Press Inc.

4. The Ministry of Sport of the Russian Federation. (2005). Development of physical culture and sports in the Russian Federation for 2006-2015 years. Retrieved from http://base. consultant.ru/cons/cgi/online.cgi?req=doc;base =LAW; $=$ $154889 ; \mathrm{fld}=134 ; \mathrm{dst}=100012 ; \mathrm{rnd}=0.7592836853582412$. [in Russian]

5. Federal Agency for Tourism. (2008). Strategy of tourism development in the Russian Federation for the period up to 2015. Retrieved from http://www.visitsiberia.info/indusrty/law/ 10_2013/strategy.pdf. [in Russian]

Submitted: February 3, 2014

Accepted: April 4, 2014 